by-and-by to become a universal possession in more or less degree.

It may require some peculiar state of mental calm or abstrac tion for this reading of the thoughts of another (apart from external expressions appreciated by the other senses) to become practicable, just as, in order to perceive distinctly the over-tones of a musical sound, it may be necessary to quench the fundamental tone.

As to the modification in the human body, supposing the sense in question to become general, this might be of a very minute character, constituting, not in the ordinary view, yet in a quite correct one, a distinct organ.

With regard to the influence of distance on the supposed serse, little, of course, can be said ; but it is perhaps noteworthy that corresponding to the gradation referred to at the outset there is a general gradation in the distance at which the sense-exciting cause is capable of operating ; from the direet contact of touch, to the action of light at the distance of a remote fixed star.

M.

\section{The Circumference of the Circle}

To some readers of NATURE the following construction will erhaps be of interest:-

Take $A O B, D C$ two diameters of a circle at right angles to one another.

Make the length of the tangent $D S$ equal to three diameters of the circle $A D B C$, then make the angle $A O P=60^{\circ}$, and

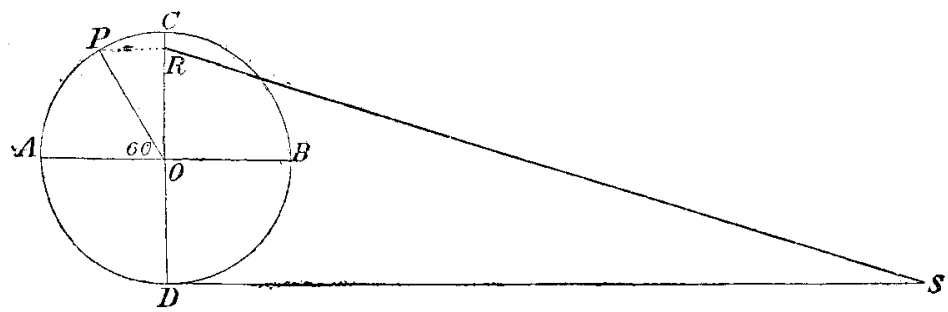

draw $P R$ at a right angle to $D C$. Connecting the points $S$ and $R$ yoa will find the length $R S$ very nearly equal to the circumference of the circle.

This will be clear from the following proof :-

From the triangle $D R S$ we have-

$$
R S=\sqrt{\overline{D R^{2}}+\overline{D S^{2}}}
$$

But taking the diameter $D C=\mathrm{r}$ the length $D S$ is $=3$, whereas $D R=O D+O P \cos 30^{\circ}=\frac{1}{2}+\frac{1}{2} \cos 30^{\circ}=0.9330127$. Therefore-

$$
\begin{aligned}
& D R^{2}=0.9330127^{2}=0.8705127 \text { and } \\
& D S^{2}=3^{2}=9.0000000 \\
& D R^{2}+D S^{2} \overline{=9.8705127} \\
& \text { value of } \pi \text { is } \\
& R S=\sqrt{D R^{2}+D S^{2}}=3^{\cdot} 141738 \text {, whereas the exact }
\end{aligned}
$$

giving a difference of $\quad 3^{\circ} 141592$, 00146 , or 0.0046 per cent.

This approximation is, of course, more than sufficient for practical purposes. Although this method has been found by me quite independently, yet I shall not be surprised to hear of its having been proposed before by others, for it is almost too simple not to hnve occurred to somebody else as well as to me.

Prague, Spálená ulice, 2 nové, January ir L. Hajniš

\section{Sun-Spots, \&c.}

I READ with interest the letter of Mr. Bedford's in NATURE, vol. xxi, p. 276, on "Sun-Spots." Perhaps the following may interest Mr. Bedford, and as I have not seen this noticed before by students of the solar orb, it may interest others besides $\mathrm{Mr}$. Bedford.

Prof. Sayce, in bis Lectures, says: "The Accadians had anticipated our almanack-makers in discovering a connection between the weather and the changes of the moon; indeed all kinds of astronomical phenomena were supposed to have an influence upon the clonds; and in anticipation, as it were, of Dr. Hunter, the same weather was expected to recur after a cycle of twelve solar years.". . . Even the appearance of the sun was not allowed to go unnoticed, and in one place we are told that on the Ist of Nisan it was "bright yellow," and in another that it was "spotted." Who, says the professor, "would have thought of looking for a notice of sun-spots in the clay tablets of ancient Babylonia?" Lectures, pp. 53-54. See also the "Astronomy and Astrology of the Babylonians," by the same, in the Transactions of the Society of Biblical Archæology, vol. iii. pp. 145,339 .

Devon and Exeter Institution, Exeter, January 27

\section{Intellect in Brutes}

IT might prove interesting to some of your readers to put the following incidents on record relative to intellect in brutes :Some time ago I kept in town a bitch and three of its puppies; the former had a strong pair of lungs and a weakness for letting the passers-by know it; when the latter became of age they exhibited all the hereditary peculiarities of the mother, and when the four animals joined in chorus, which was their favourite amusement at night, the result was anything but agreeable. Some of my friends hinted to me that if that state of things continued I should probably be indicted for causing a nuisance, and I therefore determined to explain to my four animals that they really mustn't bark. One night I remained late in town, and having provided myself with a stick, I waited till I heard one of them bark, and I immediately afterwards went out and chastised him, or rather the one I thought had made the noise. I was, however, soon met by a difficulty; although I could I was, however, soon met by a difficulty ; although I could between those of the puppies; and whilst the old one was silenced after a few chastisements, the puppies were not; probably in mistake I had thrashed the wrong puppy. I therefore hit upon the plan of making the whole four responsible for each other, and as soon as I heard any one of them bark I applied my stick freely to the whole four, the one after the other. When this had been done two or three times I heard one of the puppies bark, and the next moment it gave a pitiful squeal; the mother had it by the neck. I went ont and patted her, thus explaining that she had done well. She wagged her tail, as much as to say she understood me perfectly, and the dogs never barked again except upon the most provoking occasions.

Some other instances which I observed lately might be mertioned as tending to show that animals of a much lower class exhibit reasoning faculties. I had occasion Iately to keep some leeches and water-beetles; they were put into round open glass vessels, about six inches high and about two-thirds full of water. A medical leech which was put into one of these vessels got out, and within an hour afterwards it was found on the table and replaced in the water. Now although the vessel was left uncovered as before, this leech never again tried to get out. A horse-leech and two water-beetles, treated in the same way did the same thing once, and once only; each preferred the water to the dry table, and on being replaced they never tried to get out again; ergo, they had been taught by experience. Is this not a high order of intelligence? How many examples have we of the genus homo where so much intelligence is not exhibited? Manchester, January I 7

W. THOMSON

Sezing a letter in Nature, vol. xxi. p. 276 , with the heading of a "clever spider," puts me in mind of a circumstance that came under my own observation near Tremadoc, in North Wales, many years ago. I sat down on a bank about four o'clock in the afternoon after a long day, when I presently saw I was close to one of the common garden spiders of rather large size, with its pretty spreading net-like web about a yard from the ground; so, for want of something to do, I alarmed the spider to discover where his den was, when off he trotted about the distance of a foot to a couple of leaves nicely tied together, where he stayed perhaps ten minutes; I then saw a beetle of rather large size walking at my feet-one of those slow moving dull black ones-I am not coleopterist enongh to know its name; I picked it up and pot it in the web at a place I thought sufficiently strong to hold it, when out rushed the spider in his boldest manner. But when he saw who his visitor was, what an alteration in his manner! He drew back, and rapidly separated the cords, when down clropped the beetle on a single line, rather quickly, to within about 4 inches of the grou: d, so that he was suspended on a line about $2 \frac{1}{2}$ feet long. The spider then trotted back to his den. The beetle was now struggling in its slow, 
awkward-looking fashion. I must have stayed and watched them for about twenty minutes, when out came the spider and descended the single line to the beetle, on which he boldly rushed; after a few seconds the beetle's struggles got weaker and weaker, when the spider returned to its den ; in a few seconds more the struggles of the beetle ceased. Now, did the spider intend the beetle for its food when he cut away his web to save it from destruction from the beetle's struggles, or was that an after-thought, or why should he know it was a "creature comfort"? and was the fact of the line being so near the ground an accident, or was it premeditated? If you put a small pebble or small piece of wood in a web, a spider will let it drop altogether ; if you put a grasshopper in it he rapidly turns it round till the creature looks like a mummy; but I suppose circumstances alter cases even with spiders.

\section{JAMES R. GREGORY}

THE following fact may be of interest to those of your readers who are connected with the correspondence in your columns regarding the possession of intellect by brutes.

Having been much worried by the depredations of bandicoots (Mits giganteus) I laid three pieces of bread for them smeared with Roth and Ringeisen's phosphor paste. Next morning the pieces of bread were found near the door where they had been placed but turned upside down. The bandicoot evidently was suspicious of the poison, had turned over the bread and nibbled away all the sound portion. On the next night I smeared the poison on very thin slices of bread, leaving hardly any of it free from the paste. On this occasion the caution of the bandicoot seems to have deserted it, for the bread was eaten, and the dead animal was found next day in the garden.

Bangalore, India, January 8

Elphinstone Begbie

\section{Suicide of the Scorpion}

Apropos of the discussion on this point that has lately taken place in NATURE, will you allow me to say that I tried the experiment referred to therein a score of times at least during my long residence in India, and that I never saw the phenomenon so graphically delineated by Byron. My experiments were conducted in cholera and other camps, in the open air, often in the presence of others, and always under circumstances which could admit of no doubt. The conclusion I came to in the matter was that "the scorpion girt by fire" is too stupid or too cowardly a creature to "cure its pain by darting its sting," or anything else, "into its desperate brain." It either rushed blindly into the flames at once, and was then and there destroyed or it wandered meaninglessly about the margin of "the circle," recoiling nervously from the actual contact, or retiring as far as it could from the heat, to resume, after a short respite, its old manceuvres. I believe as the result of these incuiries that the ampression or belief created by the fine imagery of the great poet is a myth and nothing more.

Warrington

WiLl Mr. Gillman or some other tell us howe scorpions achieve suicide? The animal stings, as I know to my cost, by a backward lash out and straightening of the tail, and the force which drives the somewhat blunt point into the enemy goes on accumulating as the reversal becomes more complete, and reaches it maximum on or near the horizontal plane and at the furthest point of extension. But when the tail is drawn back above the animal's head, the point is turned npwards, and therefore away from the head, and even if it could be turned towards the head there is no possible force to drive it through the tough or hard carapace.

Can a man pummel his own back? Can a horse kick its own belly? But the feat attributed to the scorpion, apart from its moral obliquity, is physically even more triumphant.

B.

\section{Stags' Horns}

OBSERVING in a late number of NATURE a communication concerning the disappearance of stags' horns after being cast off, and a request for information upon the subject from whatever source it might be had, I venture to send the following :-

A few winters ago I spent some weeks in the woods of Georgia, where most of my time was devoted to deer-hunting.
In roaming over the woody hummocks of that country I several times stumbled upon the cast-rff antlers of bucks. Being, like your correspondent, impressed with the popular belief that these were always buried or in some way destroyed by the animals, I inquired of old hunters if it was of common occurrence to meet with them, and was told that they were not rarely found just as we had seen them upon the occasion in question. I suppose that the popular belief in their burial or destruction arose out of the fact that about the time for shedding their horns the bucks retire to the most secluded spots accessible so as to avoid disturbance by other bucks or any enemy during the first few days of the tender, velvety stage of the new horns, and into such retired places man does not commonly venture.

This brings to mind the similar habit which prevails among most crustaceans. The edible crab of this region, for example, waits for a very high tide, and goes with it far inland, where, in shelter of some dark nook, and quite away from its common enemies, it slips off the old shell and spends a few hours on land awaiting the hardening process of the new one before entering again into the struggles of life. The fishermen have learned, however, that the most favourable times for catching soft crabs is connected with certain phases of the moon, to which they attribute some mysterious infuence upon the crabs directly; of course the dependence of tides and moon solves this little mystery.

Baltimore, Maryland, U.S.A., January 22

W. BARTON

\section{MOUNTAIN BUILDING}

$\mathrm{F}$ EW problems in physical geology are more fascinating than that which deals with the origin of mountains. At the same time few present greater difficulties. In the first place it is absolutely necessary to ascertain the facts of mountain structure before proceeding to frame any theory to account for them. Yet to do this involves an amount of mere physical toil which of itself raises a formidable impediment to progress. For the mountains cannot be understood from a distance. One may not intuitively interpret them by merely looking at them from below. They must be climbed and scrutinised in detail from crest to crest and valley to valley. But to be able to understand what one sees in these elevated regions, one must have an eye that has been well trained in the observation of geological structure, and which, while losing sight of no essential detail, can yet detect the dominant lines amid the apparent disarray of crag and scar, slope and pinnacle. In the next place, having elicited the fundamental facts, it is needful to find for them some explanation which, while connecting them harmoniously and luminously, shall be in strict accordance with the laws of physics, and from the point of view of geological dynamics may be regarded as not only possible but probable.

Thus two obvious paths lead to the consideration of the subject. 'By the one we are conducted into the region of geological observation in the field. By the other we are drawn to the laboratory and the workshop, where the processes of nature can in some measure be repeated and watched. But these two roadways lie near each other, and the traveller along either of them, if he would keep himself from profitless divergence, should never lose sight of the other. Unfortunately this caution has not always been followed. Hence theories of mountain growth have been proposed, some of them wholly regardless of the real facts of mountain structure, others as defiant of physical possibilities.

Within the last few years the most detailed studies of the actual structure of mountains yet attempted have been carried out among the Alps. Chief among these are the admirable monograph of Dr. Baltzer upon the Glärnisch, and the still more remarkable and beautifully illustrated work of Prof. Heim, on the mechanism of mountainmaking. These two writers deserve the thanks of all who take interest in the many questions which the forms of the mountains never cease to raise in the mind. They

I "Der Mechanismus der Gebirgsbildung." Dr. F. Pfaff. (Heidelberg. I879.) 